\title{
Factors Associated with the Number of Substance Abuse Nonprofits in the U.S. States: Focusing on Medicaid Expansion, Certificate of Need, and Ownership
}

\author{
${ }^{1}$ Department of Public Administration, State University of New York College at Brockport, 55 St Paul Street Rochester, New \\ York, USA, E-mail: snoh@brockport.edu \\ ${ }^{2}$ Nebraska Children and Families Foundation, Associate Vice President for Research and Evaluation, Lincoln, Nebraska, USA
}

\begin{abstract}
:
The Affordable Care Act improved substance abuse service coverage and increased demand for these services. Presumably, these changes also influenced the number of substance abuse nonprofits in states. State decisions for Medicaid expansion have the potential to influence nonprofits' decisions to establish new facilities, increasing the demand for these services. In addition, Certificate of Need (CON), that is, state regulation of new health services and facilities, can affect nonprofits' responses to increased demand for substance abuse services. This study provides evidence that the number of nonprofit substance abuse facilities is negatively associated with state decisions to expand Medicaid and state regulation of new health services and facilities. However, in states with both Medicaid expansion and CON, the number of nonprofit substance abuse facilities tended to increase. In addition, evidence suggests that both nonprofit and for-profit substance abuse facilities are negatively influenced by Medicaid expansion and CON, but positively influenced by the interaction of Medicaid expansion and $\mathrm{CON}$, government spending, racial diversity, median income, and uninsured rates.
\end{abstract}

Keywords: medicaid expansion, certificate of need (CON), substance abuse facilities, ownership, the affordable care act

DOI: $10.1515 / \mathrm{npf}-2017-0010$

\section{Introduction}

Substance use disorders including opioid overuse represent urgent issues in the U.S., as indicated by President Trump's declaration that the opioid crisis is a health emergency. Approximately 64,000 people died in the United States from addiction to prescription or illicit opioids in 2016, with more than 300,000 such deaths since 2000 (Davis 2017). However, many Americans with substance use disorders have limited access to relevant services. Before enactment of the 2010 Patient Protection and Affordable Care Act (ACA), many people with these issues were uninsured or did not receive treatment due to preexisting conditions or inadequate insurance coverage (Beronio, Glied, and Frank 2014). Kamal and his associates (2017) reported " 1 in 5 people say they or a family member had to forego needed mental health services because they couldn't afford the cost, their insurance wouldn't cover it, they were afraid or embarrassed, or they didn't know where to go."

This research focuses on changes in the number of nonprofit substance abuse facilities in the 50 U.S. states between 2012 and 2016, after enactment of the ACA. The ACA improved substance use disorder coverage in the U.S. and increased demand for services; it expanded Medicaid to those below 65 years of age who earn up to $138 \%$ of the federal poverty level (FPL). Through this expansion and the creation of health insurance marketplaces, the ACA offered affordable access to mental health and substance use disorder services for millions of Americans. Consequently, the ACA has likely led to a surge in demand for services for substance use disorders, possibly necessitating more substance abuse facilities.

Nonprofit organizations have long played a major role in health care delivery in the United States. Health care nonprofits comprised $13 \%$ of all nonprofits but accounted for almost $60 \%$ of all nonprofit revenues in 2012 (Urban Institute 2014). Nonprofits are important providers of mental health services including substance abuse treatment (Gray and Schlesinger 2012). As of 2016, there were approximately 7,700 nonprofit substance abuse 
facilities, which constitute more than $50 \%$ of such facilities across the country. Types of care offered include outpatient treatment, residential (non-hospital) treatment, and hospital inpatient treatment (Substance Abuse and Mental Health Services Administration 2016). Thus, nonprofit organizations have played an essential role in treating and addressing substance use disorders, including opioid overuse, in the United States.

This study explores how state decisions about ACA Medicaid expansion and state regulation of new health services, as indicated by Certificate of Need (CON), influence the number of nonprofit substance abuse facilities, in conjunction with other factors such as government spending, racial/ethnic diversity, and uninsured rates across states. First, state decisions regarding Medicaid expansion can affect the demand for and supply of substance abuse services. The context of Medicaid expansion, with some states opting in and others opting out of the program, allows researchers to compare voluntary failure theory with government failure theory. In the states in which Medicaid expanded, substance abuse facilities can be subject to increased demand and increased federal funding for these services, in accordance with voluntary failure theory. By contrast, in states in which Medicaid did not expand, substance abuse organizations do not experience additional demand and funding, in line with government failure theory. Second, state governments are legally authorized actors to regulate health professionals and health-related organizations including health-related nonprofits. States that have enacted and operated CON legislation require health care organizations to have permission from the states before expanding or establishing new service lines or organizations. Thus, CON legislation will possibly influence nonprofits' establishing organizations to treat substance abuse-related illnesses. Third, this study investigates various factors that influence the number of nonprofit versus for-profit substance abuse facilities. Thus this extends upon the extant literature, which has tended to focus only on nonprofit organizations in this respect (Corbin 1999; Grønbjerg and Paarlberg 2001; Kim 2015; Lecy and Van Slyke 2013).

The next section explains how the ACA has influenced substance use disorder coverage including opioid overuse and demand for services. Several hypotheses are then proposed regarding state decisions about Medicaid expansion, state CON legislation, government spending, median income, race/ethnic diversity, and uninsured rates. The empirical results from our analysis are then described and explored. Finally, we discuss the implications of these findings and suggest directions for future research. This research provides evidence that, while the number of nonprofit substance abuse facilities is negatively associated with state decisions for Medicaid expansion and with state regulation of new health services, in those states with both Medicaid expansion and $\mathrm{CON}$, the number of nonprofit substance abuse facilities has tended to increase. Moreover, the number of for-profits appears to be influenced by the same factors that affect the number of nonprofit substance abuse facilities: Medicaid expansion, CON, the interaction of Medicaid expansion and CON, government spending, racial diversity, median income, and uninsured rates.

\section{The Patient Protection and Affordable Care Act (ACA) and Nonprofit Substance Abuse Organizations}

\subsection{Nonprofit Substance Abuse Facilities Serving Underprivileged Communities}

Overall, the number of substance abuse facilities increased from 13,771 in 2006 to 14,399 in 2016, as indicated in Table 1. However, a more high-resolution exploration of these data according to ownership shows that the number of nonprofit substance abuse facilities decreased by 449 while their for-profit counterparts increased by 1,294 between 2006 and 2016. In proportional terms, although $60 \%$ of substance abuse treatment facilities were provided by nonprofit organizations in 2006, by 2016 this was down to $53 \%$. In addition, in 2016, nonprofit substance abuse facilities treated around $50 \%$ of all patients, decreasing from $55.1 \%$ in 2006 . In sum, although nonprofit substance abuse facilities are still important treatment providers in terms of their prevalence and the number of patients they serve, their for-profit counterparts are becoming increasingly more prevalent and are providing services to a growing number of patients.

Table 1: Substance abuse facilities: Number and percent of facilities and patients, 2006-2016.

\begin{tabular}{lllllllll}
\hline & \multicolumn{3}{l}{ Number of Facilities (Percent) } & \multicolumn{5}{l}{ Number of Patients (Percent) } \\
\hline \multirow{3}{*}{ Nonprofit } & 2006 & 2010 & 2014 & 2016 & 2006 & 2010 & 2014 & 2016 \\
& 8,111 & 7,683 & 7,817 & 7,662 & 623,604 & 625,321 & $\mathrm{n} / \mathrm{a}$ & 568,876 \\
For-profit & $(58.9 \%)$ & $(57.6 \%)$ & $(55.2 \%)$ & $(53.2 \%)$ & $(55.1 \%)$ & $(53.2 \%)$ & $(49.4 \%)$ \\
& 3,807 & 3,985 & 4,664 & 5,101 & 328,763 & 372,525 & $\mathrm{n} / \mathrm{a}$ & 449,038 \\
& $(27.6 \%)$ & $(29.9 \%)$ & $(33.0 \%)$ & $(35.4 \%)$ & $(29.1 \%)$ & $(31.7 \%)$ & & $(39.0 \%)$
\end{tabular}




\begin{tabular}{lllllllll} 
Government & 1,853 & 1,671 & 1,671 & 1,576 & 178,514 & 177,616 & $\mathrm{n} / \mathrm{a}$ & 132,509 \\
& $(13.5 \%)$ & $(12.5 \%)$ & $(11.8 \%)$ & $(11.4 \%)$ & $(15.8 \%)$ & $(15.1 \%)$ & $(11.6 \%)$ \\
Total & 13,771 & 13,339 & 14,152 & 14,399 & $1,130,881$ & $1,175,462$ & n/a & $1,150,423$ \\
& $(100 \%)$ & $(100 \%)$ & $(100 \%)$ & $(100 \%)$ & $(100 \%)$ & $(100 \%)$ & & $(100 \%)$ \\
\hline
\end{tabular}

Source: The National Survey of Substance Abuse Treatment Services, 2016

Table 2 shows the states with the most and fewest substance abuse facilities according to ownership in 2016. For example, California had 1,430 substance abuse facilities in 2016, Whereas Delaware and Vermont had fewer than 50. California exhibits the largest number of both nonprofit and for-profit facilities. Other states such as New York and Texas show interesting variations in the number of nonprofits versus for-profits providing substance abuse treatments. New York is ranked second in terms of the former but in terms of for-profits it does not rank in the top five. Texas was home to the fifth largest number of for-profits but with relatively few nonprofits.

Table 2: Number of substance abuse facilities by states, 2016.

\begin{tabular}{|c|c|c|c|c|c|}
\hline \multicolumn{2}{|c|}{ Total Substance Abuse Facilities } & \multicolumn{2}{|l|}{ Nonprofit } & \multicolumn{2}{|l|}{ For-Profit } \\
\hline 1. California & 1430 & 1. California & 785 & 1. California & 471 \\
\hline 2. New York & 922 & 2. New York & 648 & 2. Florida & 366 \\
\hline 3. Florida & 716 & 3. Illinois & 368 & 3. Illinois & 275 \\
\hline 4. Illinois & 675 & 4. Ohio & 325 & $\begin{array}{l}\text { 4. North } \\
\text { Carolina }\end{array}$ & 260 \\
\hline $\begin{array}{l}\text { 5. Pennsylvania } \\
--\end{array}$ & 528 & $\begin{array}{l}\text { 5. Florida } \\
--\end{array}$ & 314 & $\begin{array}{l}\text { 5. Texas } \\
--\end{array}$ & 222 \\
\hline 46. North Dakota & 60 & 46. South Dakota & 33 & 46. Alaska & 12 \\
\hline 47. Wyoming & 58 & 47. New Hampshire & 32 & $\begin{array}{l}\text { 47. South } \\
\text { Dakota }\end{array}$ & 10 \\
\hline 48. Rhode Island & 52 & 48. Delaware & 27 & 48. Wyoming & 9 \\
\hline 49. Delaware & 47 & 49. Idaho & 15 & 49. Montana & 8 \\
\hline 50. Vermont & 46 & 50. North Dakota & 14 & 50. Vermont & 5 \\
\hline Total 14,399 & & Total & & & \\
\hline
\end{tabular}

Source: The National Survey of Substance Abuse Treatment Services, 2016

Nonprofit substance abuse facilities are essential for those with substance abuse problems who live in lowand moderate-income communities. The proportion of patients who depends on their own private insurance rather than on Medicaid or other public programs is critical to substance abuse facilities' profitability and financial viability. Medicaid is a public program to pay for health services for economically disadvantaged people, typically the lowest reimbursement for substance abuse facilities. As indicated in Table 3, $70 \%$ and $45 \%$ of nonprofit and for-profit substance abuse facilities, respectively, receive Medicaid. In addition, nonprofit facilities are more likely to provide sliding fee scales according to salaries and treatment at no charge for clients who cannot pay, compared to for-profit facilities. Thus, nonprofit facilities tend to emphasize charitability rather than profitability, contributing to low- and moderate-income communities whereas for-profits pay more attention to profitability. Considering the role of nonprofit substance abuse facilities in serving low- and moderate-income communities and the increasing number of for-profits in this area, it is important to understand factors affecting changes in the number of nonprofit substance abuse facilities, and investigate how the factors influence for-profit facilities.

Table 3: Types of client payments accepted, 2016.

\begin{tabular}{lllll} 
& Total & Medicaid & $\begin{array}{l}\text { Sliding fee } \\
\text { scale }\end{array}$ & $\begin{array}{l}\text { Treatment at no } \\
\text { charge for clients } \\
\text { who cannot pay }\end{array}$ \\
\hline Nonprofit & 7662 & 5478 & 5154 & 4400 \\
& $(100 \%)$ & $(71.5 \%)$ & $(67.3 \%)$ & $(57.4 \%)$ \\
For-profit & 5101 & 2292 & 2366 & 1033 \\
& $(100 \%)$ & $(45.0 \%)$ & $(46.4 \%)$ & $(20.3 \%)$ \\
\hline
\end{tabular}

Source: The National Survey of Substance Abuse Treatment Services, 2016 


\subsection{ACA and Increasing Demand for Substance Abuse Services}

Before the ACA, many people with mental health and substance abuse disorders did not seek treatment due to lack of insurance or incomplete mental health coverage. Mental illness is more prevalent among lower income groups (Beronio et al. 2014), a population less likely to have had health insurance before the ACA. In addition, many people with substance abuse issues had difficulty obtaining insurance plans because "insurers in most states could deny or underwrite coverage based on these preexisting conditions" (Beronio et al. 2014, 411). Although the 2008 Mental Health Parity and Addiction Equity Act (Parity Act) required that health insurance companies provide coverage for mental health and substance abuse services comparable to the coverage they provide for medical and surgical services, this regulation applied only to plans that already included mental health or substance abuse disorder benefits and did not sufficiently address incomparable mental health services to others.

The ACA of 2010 enhanced coverage of substance abuse disorder services. It requires that all plans offered both inside and outside marketplaces cover mental health and substance abuse disorder services. This requirement is also applicable to benefits under Medicaid expansion (Beronio et al. 2014). In addition, the ACA further increased demand for substance abuse services by creating health insurance marketplaces and expanding Medicaid, which began being implemented in 2014. Health insurance marketplaces, established in all 50 states, help low- and moderate-income individuals obtain affordable health plans and services through federally subsidized premium and cost-sharing assistance programs (Congressional Research Service 2013). With this expansion of Medicaid, people who earn up to $138 \%$ of the federal poverty level (FPL) are eligible for the program. In relation to mental health and substance use disorder coverage, an estimated 32 million Americans benefit from the ACA for access to these services (Beronio, Po, Skopec, and Glied 2014). As of March 2016, more than 11 million Americans had obtained health insurance plans through the program (Kaiser Family Foundation 2016b). As of December 2016, an additional 14 million people had gained health insurance coverage through the ACA's Medicaid expansion (Kaiser Family Foundation 2016a).

The ACA will increase overall spending on substance use disorder treatment, possibly affecting the demand for and supply of services. As indicated in Table 4, it is anticipated that total spending on treatment will grow to $\$ 42$ billion in 2020 from \$24 billion in 2009. Medicaid spending on substance use disorder treatment has grown faster than the amount spent by any other payers' spending on the treatment and will account for $28 \%$ of total substance use disorder spending in 2020, up from $21 \%$ in 2009. By contrast, in 1986 the largest single source of spending on treatment emanated from private insurance, funding over $30 \%$ of total substance use disorder spending; by 2009 this had dropped to the third largest source of spending, following Medicaid and other state and local government entities. The ACA decreased uninsured rates across the United States between 2014 and 2016, potentially leading to a surge in demand for health services (Spetz and Chapman 2015).

Table 4: Distribution of substance use disorder spending by payer, 1986-2020.

\begin{tabular}{lllll}
\hline & $\mathbf{1 9 8 6}$ & $\mathbf{2 0 0 9}$ & $\begin{array}{l}\mathbf{2 0 1 5} \\
\text { (estimated) }\end{array}$ & $\begin{array}{l}\mathbf{2 0 2 0} \\
\text { (estimated) }\end{array}$ \\
\hline $\begin{array}{l}\text { Distribution by payer } \\
\begin{array}{l}\text { Out-of-pocket } \\
\text { Private insurance }\end{array}\end{array}$ & $13 \%$ & $11 \%$ & $9 \%$ & $9 \%$ \\
$\begin{array}{l}\text { Other private } \\
\text { Medicare }\end{array}$ & $32 \%$ & $16 \%$ & $16 \%$ & $16 \%$ \\
Medicaid & $4 \%$ & $5 \%$ & $4 \%$ & $4 \%$ \\
$\begin{array}{l}\text { Other federal } \\
\text { Other state and local }\end{array}$ & $8 \%$ & $5 \%$ & $5 \%$ & $5 \%$ \\
$\begin{array}{l}\text { Total substance use } \\
\text { disorder spending }\end{array}$ & $11 \%$ & $21 \%$ & $25 \%$ & $28 \%$ \\
\hline
\end{tabular}

Source: Projections of National Expenditures for Treatment of Mental and Substance Use Disorders, 2010-2020

\subsection{State Variation in Medicaid Expansion and Certificate of Need (CON)}

Out of the two programs under the ACA that commenced in 2014, this research focuses on ACA Medicaid expansion. This is because although not all states have chosen to expand Medicaid, they all have a health insurance marketplace regardless of state-own or federally-facilitated ones. As of 2017, 31 states and the District of Columbia have expanded Medicaid, and 19 states have chosen not to do so. Empirical evidence suggests that 
residents in Medicaid-expansion states are more likely to have insurance, compared to those in no-expansion states (Courtemanche, Marton, Ukert, Yelowitz, and Zapata 2017; Kaestner, Garrett, Chen, and Gangopadhyaya 2017). Thus, state decisions about whether to expand Medicaid have affected access to affordable substance abuse services and possibly influenced the number of substance abuse nonprofits.

Moreover, health care providers' decisions to establish new facilities, or acquire or expand existing facilities can be affected by state regulation of health services, that is, Certificate of Need (CON). Extant legislation requires health care service providers to have permission from state agencies to enter a market or to expand an existing facility. The goals of $\mathrm{CON}$ are to facilitate coordinated planning of new services and facility construction, possibly affecting market entry of new nonhospital and hospital providers (Rahman et al. 2016). As of 2016, 34 states have some form of CON legislation while others do not (National Conference of State Legislatures 2016). Empirical findings report that market entry of new nonhospital and hospital providers is lower (higher) in states with (without) CON legislation (Harrington et al. 1997; Stratmann and Baker 2017). Thus, in the states with $\mathrm{CON}$, the number of nonprofit substance abuse facilities will be influenced by state regulation of new health services.

State decisions about ACA Medicaid expansion permit researchers to test dominant theories frequently cited in the nonprofit literature to explain the existence of the nonprofit sector and nonprofit organizations. These dominant theories include market/government failure, contract failure, and voluntary failure. Market failure theory, which arises from the work of Weisbrod (1977), posits that nonprofit organizations develop and exist to provide services for which there is a demand but which the government does not provide because these services are demanded by a minority, rather than the majority. Somewhat similarly, the government failure theorists argue that "nonprofit organizations are gap-fillers; they exist as a result of private demands for public goods not offered by the public sector" (Anheier 2014, 203). This theory predicts more nonprofit organizations in a heterogeneous society (Grønbjerg and Paarlberg 2001) while individuals living in low-income communities will have less access to nonprofits (Allard 2008). Like market failure theory, contract failure theory also focuses on who is demanding the services; however, contract failure theory suggest that it is not the fact that only a minority demands the services but rather the fact that consumers of nonprofit services are often not the same as the purchaser. As a result, purchasers will prefer services provided by nonprofits over services provided by government or business because nonprofits are perceived to be more trustworthy. In other words, nonprofit organizations provide a proxy assurance to the purchaser that the goods or services meet adequate standards. Both market failure theory and contract failure theory — both of which have been in use since the early 1980ssuggest that the nonprofit sector fills a gap when market conditions make it such that the government does not provide certain services, yet there is still a demand for these services. The theory of voluntary failure-the most recently introduced of these three theories - suggests the opposite. In other words, government steps in when voluntary action proves insufficient, rather than the reverse. Thus, voluntary action would generally be the primary and dominant source of services, but due to factors such as philanthropic insufficiency, philanthropic particularism, and philanthropic paternalism, the voluntary sector may fail to fully address demand. In this case, the government must step in to fill resulting gaps (Salamon 1987; Salamon and Anheier 1998).

States with Medicaid expansion can be regarded as those in which the federal government financially supports substance abuse nonprofits to deliver substance abuse services, in line with voluntary failure theory. Beyond insuring more people, states with Medicaid expansion provide substance abuse nonprofits with a predictable federal funding source. To cover the costs associated with the relaxed eligibility criteria involved under Medicaid expansion, the federal government provided $100 \%$ of funding to states from 2014 to 2016, which is now slowly reducing until it reaches $90 \%$ in 2020. In states exhibiting Medicaid expansion, nonprofit substance abuse facilities can rely on predictable funding from the federal government for Medicaid patients. In contrast, substance abuse nonprofits in states without Medicaid expansion did not have this opportunity to receive the newly established federal funding, in line with government failure theory. Thus, state decisions for Medicaid expansion are related to additional governmental support for substance abuse facilities, whereas state decisions against the program are related to governmental inaction or failure to support substance abuse nonprofits.

This research focuses on investigating the effects of varying state interventions in the health policy domain, that is, state decisions about ACA Medicaid expansion and state operation of CON to regulate the supply of health services. The extant nonprofit literature shows that the number of nonprofits across states or counties is influenced by various factors including governmental interventions (e. g., Kim 2015; Lecy and Van Slyke 2013; Saxton and Benson 2005), median household income (e. g., Kim 2015; Saxton and Benson 2005), racial/ethnic diversity (e. g., Corbin 1999; Kim 2015), and market failure or problem severity (e. g., Corbin 1999). However, little scholarly attention has been paid to how nonprofits are influenced by state decisions regarding health policy. In the health policy domain, nonprofit or for-profit substance abuse facilities are under state regulation and are affected by state officials' decisions (e. g., Krinn, Karaca-Mandic, and Blewett 2015; Longest 2016; Noh and Krane 2016). 
In addition, this study is interested in the interaction of Medicaid expansion and CON. There is a need to study the effects of bundled policy interventions on expected goals, because state governments have bundled a variety of policies rather than relying on a single intervention, yet this has hitherto been neglected in the literature (Eliadis, Hill, and Howlett 2005; Feiock, Stream, and Tavares 1998; Howard 2002; Howlett 2011; Kassekert and Feiock 2009). Further, prior studies have paid little attention to the role of CON in relation to other state decisions about health policy (e. g., Harrington et al. 1997; Rahman et al. 2016). State implementation of both Medicaid expansion and CON can exert contrasting influences on nonprofits in states: Medicaid expansion can increase demand for substance abuse services, whereas state operation of CON is related to regulating new services and facilities. Thus, this research explores how the number of substance abuse nonprofits is associated with Medicaid expansion, $\mathrm{CON}$, and the interaction of both, along with other factors including governmental intervention, median household income, racial/ethnic diversity, and problem severity.

Moreover, this research examines various factors that influence the number of nonprofit versus for-profit substance abuse facilities, to which little scholarly attention has been paid. Prior studies have reported various factors that affect the number of nonprofits (Corbin 1999; Grønbjerg and Paarlberg 2001; Kim 2015; Lecy and Van Slyke 2013). However, it is unclear whether those factors also influence the number of for-profit entities. Considering their differential legal and market-imposed constraints (Goddeeris and Weisbrod 1998; Galaskiewicz, Mayorova, and Duckles 2013), it is reasonable to expect that the factors that affect the number of substance abuse facilities may differ between for-profits and nonprofits.

\section{Methods}

To investigate how the number of nonprofit substance abuse facilities is influenced by state decisions about Medicaid expansion and state operation of CON legislation, this study uses fixed-effects panel models with robust standard errors, using data from 50 states between 2012 and 2016. Even though the ACA was enacted in 2010, Medicaid expansion did not begin until 2014. A difference-in-differences approach is not taken because states did not decide to adopt Medicaid expansion in one specific year, but rather the extent of expansion, or lack thereof, varies from 2012 to 2016. In addition, the initial analyses using difference-in-difference models showed that the difference-in-difference estimator was omitted due to collinearity for all models, not allowing researchers to interpret the interaction of the expansion state indicator with the post period indicator.

Four models predicting the number of substance abuse facilities in states were tested. Models 1 and 2 include, respectively, a subset of the independent variables relevant to the number of nonprofit substance abuse facilities and a more comprehensive suite of independent variables. Models 3 and 4 include, respectively, a subset of the independent variables relevant to the number of for-profit substance abuse facilities and a more comprehensive suite of independent variables. Time fixed effects were not included because testing for the effects failed to reject the null hypothesis that the coefficients for all years are jointly equal to zero. As robustness checks, control variables were added one by one to the models only with the key variables, and it turned out that they did not influence the directions of the key explanatory variables.

\subsection{Data for Dependent Variables: Substance Abuse Facilities}

The dependent variables are (1) the number of nonprofit substance abuse facilities per 10,000 state residents; and (2) the number of for-profit substance abuse facilities per 10,000 state residents between 2012 and 2016. These dependent variables allow us to study how state decisions about health policy influence levels of substance abuse facilities in states before and after the implementation of ACA Medicaid expansion, which began in 2014. The dependent variables are coded using data from the National Survey of Substance Abuse Treatment Services (N-SSATS) between 2012 and 2016 available from the Substance Abuse and Mental Health Services Administration.

\subsection{Data for Explanatory Variables}

Medicaid expansion. State decisions to expand Medicaid affect demand for substance abuse services, possibly influencing the number of substance abuse nonprofits. The Kaiser Family Foundation (2014) reported that residents of the 19 states that did not expand Medicaid are less likely to be insured than the residents of those states that did expand coverage. Medicaid eligibility levels in the 19 non-expansion states have remained low, negatively affecting demand for substance abuse services. Thus, states that expanded Medicaid are likely to 
have higher demand for substance abuse services, possibly resulting in a larger number of mental health nonprofits in those states. States that expanded Medicaid under the ACA between 2012 and 2016 are coded as 1, and 0 otherwise. All states are coded 0 in 2012 and 2013 because Medicaid expansion began in 2014.

Certificate of Need (CON). State regulation of new health services, that is, CON, can affect the number of nonprofit substance abuse facilities in a state (Rahman et al. 2016). In the states with CON, health care providers need to wait for state officials' approval after submitting documents to rationalize why the states need new facilities or new service lines. This process can delay or prevent the establishment of new substance abuse facilities. States with CON are coded as 1, and 0 otherwise. Data for this variable emanate from the National Conference of State Legislatures.

The interaction of Medicaid expansion and CON. In terms of state decisions about Medicaid expansion and state operation of $\mathrm{CON}$, there are four groups of states: (1) states with both Medicaid expansion and CON; (2) states with Medicaid expansion only; (3) states with CON only; and (4) states with neither Medicaid expansion or CON. To capture state level variations in Medicaid expansion and CON, the interaction of these two variables is included. Medicaid expansion is related to increasing demand for substance abuse services and $\mathrm{CON}$ is legislation to regulate health service supply in a state. Considering their contrasting aspects, it is reasonable to expect that their interaction will negatively influence the number of substance abuse nonprofits.

\subsection{Data for Control Variables}

Government spending. Voluntary failure theory states that, to take advantage of nonprofits' experience and extensive networks, governments invite them to take part in the implementation of public policies, programs, and projects. Governments financially assist nonprofits that deliver public goods and services, which can affect the size of the nonprofit sector. Lecy and Van Slyke (2013) and Kim (2015) provide evidence that government funding positively affects nonprofit density, supporting voluntary failure theory. Accordingly, states with higher spending on substance abuse disorders will likely have more substance abuse nonprofits. To capture levels of government spending related to substance abuse facilities, the natural logarithm of state and local government spending on hospitals, health, and public welfare between 2012 and 2015 is included. For 2016, 2015 data were replicated due to data unavailability. The data capture state and local governments' own funds and federal grants allocated to state and local governments (e.g., Substance Abuse and Mental Health Block Grants) to address substance abuse disorder issues. Data for this variable are taken from the U.S. Census Federal, State, and Local Governments.

Median income. Median household income is an indicator of whether a state's economy enables residents to support nonprofit organizations. Prior research reports that affluent communities likely have more community support for nonprofits whereas low-income communities tend to have fewer resources for the nonprofit sector (Grønbjerg and Paarlberg 2001; Lecy and Van Slyke 2013). Lecy and Van Slyke (2013) reported that median income positively affected the number of human services-related nonprofits, whereas Kim (2015) found that median household income was negatively associated with the number of health-related nonprofits. Accordingly, states with higher median income will likely provide more resources for substance abuse nonprofits, resulting in more of these entities in those states. Median income is measured by the natural logarithm of median household income between 2012 and 2016 taken from the U.S. Census American Community Survey.

Racial diversity. According to government failure theory, people rely on nonprofit organizations in areas of government failure, positively affecting the number of nonprofits. In a heterogeneous society, more nonprofit organizations would be expected where demands for public goods are much diverse (Kingma 2003). Accordingly, a state with a more diverse racial/ethnic population is likely to exhibit more heterogeneous demand for substance abuse services, resulting in more substance abuse nonprofits. The reversed Herfindahl-Hirschman index is used to measure the level of racial/ethnic diversity between 2012 and 2015, and for 2016, data from 2015 were replicated due to data unavailability. This diversity index is calculated as one minus the sum of squares of the share of Non-Hispanic Whites, Hispanic or Latino, Black, and others in a state, and then the index is reversed for ease of interpretation. A higher score indicates more racial/ethnic diversity. Data for this variable derive from the U.S. Census American Community Survey.

Uninsured rates. Uninsured rates indicate whether problem severity affects the number of substance abuse nonprofits in states. High uninsured rates are related to governmental inaction or failure to address the inability of citizens to access affordable health coverage. In a state with a higher uninsured rate, residents will depend on substance abuse nonprofits for services, resulting in more of these entities being established and maintained. Data for uninsured rates come from the American Community Survey between 2012 and 2016.

Based on these variables, the analysis described in the next section tests the following hypotheses.

Hypothesis 1: A state that expanded Medicaid will be associated with a larger number of substance abuse nonprofits. 
Hypothesis 2: A state with CON will be associated with a smaller number of substance abuse nonprofits.

Hypothesis 3: A state exhibiting both Medicaid expansion and CON will be associated with a smaller number of substance abuse nonprofits.

Hypothesis 4: A state with a larger government sector will be associated with a larger number of substance abuse nonprofits.

Hypothesis 5: A state with a higher median income will be associated with a larger number of substance abuse nonprofits.

Hypothesis 6: A state with a more diverse racial-ethnic population will be associated with a larger number of substance abuse nonprofits.

Hypothesis 7: A state with a higher uninsured rate will be associated with a larger number of substance abuse nonprofits.

After testing the effects of the factors of interests on substance abuse nonprofits, this research investigates whether the factors also influence the number of for-profit substance abuse facilities in states.

\section{Findings}

The results in Table 5 show that the number of substance abuse nonprofits was negatively associated with state decisions about Medicaid expansion and state operation of CON. This research hypothesized that a state with Medicaid expansion would be associated with a larger number of substance abuse nonprofits. Thus, this evidence does not provide evidence that government engagement positively influences the number of nonprofit organizations. State operation of CON negatively influenced the number of substance abuse nonprofits supporting Hypothesis 2. However, the interaction term of the two variables shows that, in a state with both Medicaid expansion and CON, the number of substance abuse nonprofits tended to increase, compared to other states. In addition, state decisions about Medicaid expansion and CON were associated with the number of for-profit substance abuse facilities similar to their nonprofit counterparts.

Table 5: The number of substance abuse facilities per 10,000 state resident in states, 2012-2016.

\begin{tabular}{lllll}
\hline & $\begin{array}{l}\text { Nonprofit } \\
\mathbf{( 1 )}\end{array}$ & $\mathbf{( 2 )}$ & $\begin{array}{l}\text { For-profit } \\
\mathbf{( 1 )}\end{array}$ & $\mathbf{( 2 )}$ \\
\hline Medicaid-expansion & $-0.178^{* *}$ & $-0.186^{*}$ & $-0.120^{* *}$ & $-0.164^{* *}$ \\
& $(-6.12)$ & $(-4.00)$ & $(-6.59)$ & $(-6.25)$ \\
CON & $-0.150^{* *}$ & $-0.107^{* *}$ & $-0.181^{* *}$ & $-0.153^{* *}$ \\
& $(-6.86)$ & $(-9.72)$ & $(-13.99)$ & $(-6.22)$ \\
Medicaid-expansion*CON & $0.232^{*}$ & $0.233^{* *}$ & $0.151^{* *}$ & $0.136^{* *}$ \\
Government Spending (Log) & $(4.53)$ & $(7.56)$ & $(8.30)$ & $(4.95)$ \\
& & $0.414^{* *}$ & & $0.448^{* *}$ \\
Racial Diversity (reverse) & & $(7.69)$ & & $(10.01)$ \\
& & $0.182^{* *}$ & & $0.146^{*}$ \\
Median Income (Log) & & $(6.22)$ & & $(4.24)$ \\
& & $0.869^{*}$ & & $0.702^{*}$ \\
Uninsured Rates & & $(4.17)$ & & $(2.89)$ \\
& & $0.0381^{* *}$ & & $0.0226^{*}$ \\
N & & $(14.82)$ & & $(4.60)$ \\
R-squared & 250 & 250 & 250 & 250 \\
\hline
\end{tabular}

Note: ${ }^{*} p<0.05,{ }^{* *} p<0.01 . t$ statistics are in parentheses.

Table 5 shows that government spending was positively associated with nonprofits providing substance abuse treatment at the 0.01 level, providing support for Hypothesis 4 . States with higher government spending on health, hospitals, and public welfare tended to have more substance abuse nonprofits. This finding accords with previous research reporting a positive relationship between government spending and the number of nonprofits (Kim 2015; Lecy and Van Slyke 2013). Like nonprofits, the number of for-profit facilities was positively associated with government spending.

Regarding Hypothesis 5, higher median income was positively related to the number of substance abuse nonprofits in a state at the 0.05 level, supporting the finding of Lecy and Van Slyke (2013). Median household income was also associated with the number of for-profit substance abuse facilities in states, indicating that this economic variable influences the number of substance abuse facilities regardless of ownership. 
Racial/ethnic diversity appeared to affect the number of substance abuse nonprofits (Hypothesis 6) in states. This finding accords with prior research suggesting that nonprofits are likely to flourish in a state with a more diverse racial/ethnic population to fulfill varied community needs (Lecy and Van Slyke 2013). Racial/ethnic diversity was also positively associated with for-profit facilities in states. Uninsured rates were also positively related to substance abuse nonprofits and for-profits in states.

\section{Discussion and Implications}

The ACA increased demand for substance abuse services through the creation of health insurance marketplaces and Medicaid expansion, necessitating more substance abuse service providers. However, states have exhibited differential preferences vis-à-vis Medicaid expansion, and they exhibit varying regulatory powers in terms of the supply of new health services. To establish substance abuse facilities in a state with CON, it is necessary for the relevant nonprofits and for-profits to receive state approval, which is costly in terms of time and effort. It was hypothesized that Medicaid expansion would be positively associated with the number of substance abuse nonprofits. By contrast, we hypothesized that CON was negatively associated with the number of nonprofits providing substance abuse treatment. The results herein provide evidence that the number of nonprofit substance abuse facilities has been influenced by state decisions about Medicaid expansion and state operation of CON. However, although the number of nonprofit substance abuse facilities was negatively associated with state decisions for Medicaid expansion and state operation of $\mathrm{CON}$, it was positively associated with the interaction of these variables. In addition, evidence suggests that, regardless of ownership, substance abuse facilities are influenced by a variety of factors including Medicaid expansion, CON, government spending, racial diversity, median income, and uninsured rates.

This research reports that Medicaid expansion was negatively associated with the number of substance abuse nonprofits. The number of substance abuse for-profits was also negatively affected by state decisions for Medicaid expansion. These unexpected findings can be attributed to political conflicts surrounding state implementation of the ACA and hidden federal rules in Medicaid. First, nonprofits may hesitate to establish new facilities due to political conflicts surrounding ACA implementation. As well reported in prior studies (e. g., Noh and Krane 2016), even in 2013, just 1 year before the implementation of Medicaid expansion and health insurance marketplaces under the ACA, some states hesitated to opt into the programs, rather than eagerly pursuing the creation of marketplaces or the expansion of Medicaid. Where political uncertainties prevail, it might not be easy for nonprofit or for-profits to make decisions concerning new facilities. Second, a hidden federal rule in Medicaid might influence nonprofits' decision making. Residential substance abuse treatment facilities are subject to a federal requirement that Medicaid cover such treatment in community-based programs when they have no more than 17 beds (Goodnough 2014). This federal rule would bar millions of addicts eligible for expanded Medicaid from entering residential programs, which could possibly and plausibly be associated with substance abuse nonprofits' hesitance to establish new such ventures. There is ample scope for future research to explore how Medicaid changes enacted by the Trump administration will affect the number of substance abuse facilities over time.

This study provides evidence that state operation of CON influenced the number of substance abuse nonprofits, an issue which has hitherto been neglected in the literature. As expected, the findings showed that state regulation of new services and facility construction was negatively associated with the dependent variable, supporting prior research (Rahman et al. 2016). Considering the role of state policy decisions in the health policy domain, it would be interesting for future research to investigate how a variety of state policy interventions influences the nonprofit sector.

Moreover, the findings show that 1) growth in the number of substance abuse nonprofits was positively associated with state regulation of health services (specifically, both Medicaid expansion and CON), and 2) the factors affecting nonprofits also influenced for-profits providing substance abuse services. These findings provide several contributions to nonprofit research and, in particular, contribute to theory building in the field. As discussed at the outset of this paper, market/government failure, contract failure, and voluntary failure are among the dominant frameworks currently used to explain the existence and growth of the nonprofit sector and nonprofit organizations. The fact that this study finds that growth in the number of substance abuse nonprofits was positively associated with state regulation of health services (specifically, both Medicaid expansion and $\mathrm{CON}$ ) tends to suggest that voluntary failure theory is most relevant. In other words, state-level decisions to expand Medicaid are indicative of voluntary failure-states are stepping in where the nonprofit sector alone has proved insufficient. However, what is most interesting is that Medicaid expansion alone was not related to growth in the number of nonprofit organizations-nor was CON alone. It was only the combination of the two. Thus, this study's results suggest other, important aspects may bear consideration in future theory building. 
For example, this study suggests that the type of state-level decision making processes in existence may play a mediating role in the contours of the nonprofit sector within each state. Furthermore, the fact that this study finds that the same factors contribute to growth in the number of both nonprofit organizations and for-profit organizations suggest the irrelevance of contract failure theory to this situation. And, whatever theoretical process is at work, it is not exclusive to the nonprofit sector and nonprofit organizations. Thus, further theoretical refinement may be needed in order for these theoretical frameworks to speak exclusively to nonprofit organizations' existence. Alternatively, it may be that in this study's sub-sector of interest-healthcare and substance abuse-lines between nonprofit organizations and for-profit organizations have become blurred to the extent that theoretical refinement no longer makes sense.

The analyses reported here has several shortcomings. First, it will be beneficial for future research to adopt difference-in-difference models to compare the post Medicaid expansion period to the pre period, as utilized in prior ACA Medicaid expansion literature (e. g., Courtemanche et al. 2017; Kaestner et al. 2017). Second, although fixed-effects panel models permit researchers to control for systematic differences among states, it would be beneficial to include variables to measure how state health policy histories have affected substance abuse nonprofits. Third, although 5 years of data were used, it is necessary to investigate changes in the number of substance abuse nonprofits over a longer time period. Fourth, this research included a government spending variable to capture levels of state and local governments' own spending and federal grants to them to address substance abuse issues in a state. For future research, it will be beneficial to include a variety of variables to indicate other sources beyond federal, state, and local governments.

However, the findings suggest that when deciding whether to establish new facilities to meet increased demands for substance abuse services, nonprofits need to consider state decisions about Medicaid expansion and to comply with state regulation of new health services (that is, $\mathrm{CON}$ ), along with responding to external factors including median income and racial diversity. In addition, the analyses suggest that during the study period nonprofits and for-profits that deliver substance abuse treatment responded commonly to Medicaid expansion, state operation of CON, government spending, median income, racial diversity, and uninsured rates.

Understanding factors associated with the number of substance abuse nonprofits is an important issue for health policy and administration. This study provides a description of how the number of substance abuse nonprofits and for-profits changed between 2012 and 2016 after enactment of the ACA. Furthermore, the findings presented here suggest that the number of substance abuse nonprofit organizations was associated with state-level governmental decisions regarding health policy and administration. Future research may want to investigate how varying state regulations influence nonprofits. Moreover, the factors that affect the number of nonprofit and for-profit substance abuse facilities appear to coincide, but the extent to which this applies in other contexts is certainly worthy of exploration.

\section{References}

Allard, Scott W. 2008. Out of Reach: Place, Poverty, and the New American Welfare State. Yale University Press.

Anheier, Helmut K. 2014. Nonprofit Organizations: Theory, Management, Policy. London and Newyork: Routledge Taylor \& Fransic Group.

Beronio, Kirsten, Sherry Clied, and Richard Frank. 2014. " How the Affordable Care Act and Mental Health Parity and Addiction Equity Act Greatly Expand Coverage of Behavioral Health Care." The Journal of Behavioral Health Services \& Research 41(4): 410-428.

Beronio, Kirsten, Po Rosa, Laura Skopec, and Sherry Clied. 2014. “ Affordable Care Act Will Expand Mental Health and Substance Use Disorder Benefits and Parity Protections for 62 Million Americans." Mental Health 2.

Congressional Research Service. 2013. "Health Insurance Exchanges under the Patient Protection and Affordable Care Act (ACA)". Washington, D.C.: CRS-7-5700 (January). Accessed July 14 2014. https://www.fas.org/sgp/crs/misc/R42663.pdf

Corbin, J. 1999. "A Study of Factors Influencing the Growth of Nonprofits in Social Services." Nonprofit and Voluntary Sector Quarterly 28: 296312.

Courtemanche, Charles, James Marton, Benjamin Ukert, Aaron Yelowitz, and Daniela Zapata. 2017. “Early Impacts of the Affordable Care Act on Health Insurance Coverage in Medicaid Expansion and Non-Expansion States." Journal of Policy Analysis and Management 36: 178-210.

Davis, Julie Hirschfeld. 2017. "Trump Declares Opioid Crisis a ‘Health Emergency’ but Requests No Funds." Accessed January 28 2018. Retrieved from https://www.nytimes.com/2017/10/26/us/politics/trump-opioid-crisis.html

Eliadis, Pearl, Margaret M Hill, and Michael Howlett. 2005. “Introduction." In Designing Covernment: From Instruments to Covernance, edited by P. Eliadis, M.M. Hill and M. Howlett, 3-18. Montreal: McGill-Queen's University Press.

Feiock, Richard C., Christopher Stream, and Antonio Tavares. 1998. “Explaining the Choice of Policy Instruments for State Environmental Protection: A Political Economy Approach." In Annual Meeting of the Western Political Science Association, Los Angeles.

Galaskiewicz, Joseph, Olga V Mayorova, and Beth M Duckles. 2013. "Studying the Roles of Nonprofits, Government, and Business in Providing Activities and Services to Youth in the Phoenix Metropolitan Area." The ANNALS of the American Academy of Political and Social Science 647: 50-82.

Coddeeris, John H., and Burton A Weisbrod. 1998. Conversion from Nonprofit to For-Profit Legal Status: Why Does It Happen and Should We Care?, 97-14. Institute for Policy Research at Northwestern University. 
Coodnough, Abby. 2014. “Obscure Rule Restricts Health Law's Expansion of Care for Addicts.” New York Times. Accessed January 282018. Retrieved from https://www.nytimes.com/2014/07/11/health/obamacare-substance-abuse-treatment-hurdles.html?_r=0

Gray, Bradford H., and Mark Schlesinger. 2012. "Health Care." In The State of Nonprofit America, edited by L.M. Salamon, 89-136. Brookings Institution Press.

Grønbjerg, K., and L. Paarlberg. 2001. "Community Variations in the Size and Scope of the Nonprofit Sector: Theory and Preliminary Findings." Nonprofit and Voluntary Sector Quarterly 30: 684-706.

Harrington, Charlene, James H Swan, John A Nyman, and Helen Carrillo. 1997. “The Effect of Certificate of Need and Moratoria Policy on Change in Nursing Home Beds in the United States." Medical Care 35(6): 574-588.

Howard, Christopher. 2002. "Tax Expenditures." In The Tools of Covernment: A Guide to the New Covernance, edited by L.M. Salaman and O.V. Elliot, 410-444. Baltimore: Johns Hopkins University Press.

Howlett, M. 2011. Designing Public Policies: Principles and Instruments. New York, NY: Routledge.

Kaestner, R., B. Garrett, J. Chen, A. Gangopadhyaya, and C. Fleming. 2017. " Effects of ACA Medicaid Expansions on Health Insurance Coverage and Labor Supply." Journal of Policy Analysis and Management 36(3): 608-642.

Kaiser Family Foundation. 2014. "The Coverage Gap: Uninsured Poor Adults in States that Do Not Expand Medicaid." Accessed January 12 2017. Retrieved from http://kff.org/health-reform/issue-brief/the-coverage-gap-uninsured-poor-adults-in-states-that-do-not-expandmedicaid/

Kaiser Family Foundation. 2016a. "Medicaid Expansion Enrollment." January 12 2017. Retrieved from http://kff.org/health-reform/stateindicator/medicaid-expansion-enrollment/view/print/?currentTimeframe=0\&print=truethe

Kaiser Family Foundation. 2016b. "Marketplace Plan Selections by Enrollment Type." January 12 2017. Retrieved from http://kff.org/healthreform/state-indicator/marketplace-plan-selections-by-enrollment-type/?currentTimeframe $=0$

Kamal, Rabah, Cynthia Cox, and David Rousseau. 2017. " Costs and Outcomes of Mental Health and Substance Use Disorders in the US." JAMA 318(5): 415-415.

Kassekert, A., and R. Feiock. 2009. "Policy Tool Bundling: Predicting the Selection and Impact of Policy Instruments Using Bayesian Methods." In annual meeting of the American Political Science Association, Toronto, Ontario, Canada.

Kim, M. 2015. "Socioeconomic Diversity, Political Engagement, and the Number of Nonprofit Organizations in U.S. Counties." American Review of Public Administration 45: 402-416.

Kingma, Bruce R. 2003. "Public Good Theories of the Nonprofit Sector." In The Study of the Nonprofit Enterprise, edited by H.K. Anheier and A. Ben-Ner, 53-65. Boston, MA: Springer.2003

Krinn, K., P. Karaca-Mandic, and L. A. Blewett. 2015. “State-Based Marketplaces Using 'Clearinghouse' Plan Management Models are Associated with Lower Premiums." Health Affairs 34: 161-169.

Lecy, J., and D. Van Slyke. 2013. "Nonprofit Sector Growth and Number: Testing Theories of Government Support." Journal of Public Administration Research and Theory 23: 189-214.

Longest, B. B. 2016. Health Policymaking in the United States, 6th ed. Chicago, IL: Health Administration Press.

National Conference of State Legislatures. 2016. “CON-Certificate of Need State Laws." Accessed January 29 2018. Retrieved from http://www.ncsl.org/research/health/con-certificate-of-need-state-laws.aspx

Noh, Shihyun, and Dale Krane. 2016. "Implementing the Affordable Care Act Health Insurance Exchanges: State Covernment Choices and Policy Outcomes." Publius: the Journal of Federalism 46: 416-440.

Peters, B. Guy, and Frans K.M. Van Nispen. 1998. Public Policy Instruments: Evaluating the Tools of Public Administration. MA: Edward Elgar Publishing.

Rahman, Momotazur, Omar Calarraga, Jacqueline S. Zinn, David C. Crabowski, and Vincent Mor. 2016. “The Impact of Certificate-Of-Need Laws on Nursing Home and Home Health Care Expenditures." Medical Care Research and Review 73: 85-105.

Salamon, Lester M. 1987. "Of Market Failure, Voluntary Failure, and Third-Party Government: Toward a Theory of Government-Nonprofit Relations in the Modern Welfare State." Nonprofit and Voluntary Sector Quarterly 16: 29-49.

Salamon, Lester M., and Hekmut K Anheier. 1998. " "Social Origins of Civil Society: Explaining the Nonprofit Sector Cross-Nationally." Volun$\operatorname{tas} 9(3): 213-248$.

Saxton, Gregory D., and Michelle A Benson. 2005. "Social Capital and the Growth of the Nonprofit Sector." Social Science Quarterly 86: 16-35.

Spetz, J., and S. A. Chapman. 2015. "The Health Workforce." In Jonas \& Kovner's Health Care Delivery in the United States, 11th ed., edited by ].R. Knickman and A.R. Kovner, 213-225.

Stratmann, T., and Matthew C Baker 2017. "Barriers to Entry in the Healthcare Markets: Winners and Losers from Certificate-of-Need Laws." Retrieved from https://www.mercatus.org/publications/barriers-to-entry-healthcare-markets-con-laws

Substance Abuse and Mental Health Services Administration. 2016. "National Survey of Substance Abuse Treatment Services (N-SSATS): Data on Substance Abuse Treatment Facilities." Retrieved from https://www.samhsa.gov/data/sites/default/files/2016_NSSATS.pdf

Urban Institute. 2014. "The Nonprofit Sector in Brief." Accessed March 3 2017. http://www.urban.org/sites/default/files/publication/33711/413277The-Nonprofit-Sector-in-Brief-.PDF

Weisbrod, B. 1977. The Voluntary Nonprofit Sector. Lexington, MA: Lexington Books. 